Gullstrand Medal by the Swedish Medical Society of Stockholm in December, 1942. He had a taciturn and gruff manner, but in spite of this his personality was impressed on his patients who had the greatest confidence in him.

\title{
ARTHUR DONALD GRIFFITH
}

ARThuR DONALD GRIFFITH, who died on March 4, after a protracted illness which he bore with characteristic calmness, was born on October 20,1882. The son of Arthur Griffith, who survives him, he forsook the legal traditions of his family for the practice of

medicine, qualifying in 1905 and obtaining the Fellowship of the Royal College of Surgeons in 1909. A student of King's College Hospital, he held various junior appointments at his training school and also at the Royal Free Hospital, and in 1909 was appointed to the honorary staff of the Royal Eye Hospital, where he had previously served as House-Surgeon, Registrar and Pathologist. He combined his duties at the Royal Eye Hospital with service as Ophthalmic Surgeon at the Westminster Hospital.

A member of the Territorial Army, which he joined on its formation, Griffith served abroad from the outbreak of hostilities in 1914 till 1919. He was Ophthalmic Specialist and Officer-inCharge of Military Hospital, Hamrum, Malta, from 1914 to 1916, Surgeon Specialist at Salonika, 1916-17, and Senior Medical Officer, Faenza area, Italy, in 1918-19. He was mentioned in despatches and created Cavaliere Corona d'Italia. His War experiences are recorded in a valuable article on "Injuries of the Eye and Orbit" which appeared in the Lancet in 1916.

Returning to civil life, Griffith rapidly established himself as an exceptionally accomplished and judicious ophthalmologist. Equally at home in the laboratory, out-patient department and operating theatre, his special interests were stereoscopic vision and radio-: therapy, as his many contributions to the Transactions of the Ophthalmological Society and Proceedings of the Royal Society of Medicine testify. These papers reveal the characteristic thoroughness that marked all his work, $\mathrm{He}$ was a fine linguist and had an exceptional knowledge of ophthalmic literature which made him an ideal contributor of articles on eye disease in successive issues of Short's Index of Prognosis. Glioma of the retina particularly fascinated him and it is fitting that a posthumous paper on the subject - to appear soon in these pages - should have been his last literary contribution. His services to his chosen speciality were perhaps greatest in his effective contributions towards the development of the research and teaching activities of the Royal Eye Hospital.

Griffith well nigh epitomised the ideal surgeon. A broad humanity permeated his personal relations ; and his scrupulousness determined 


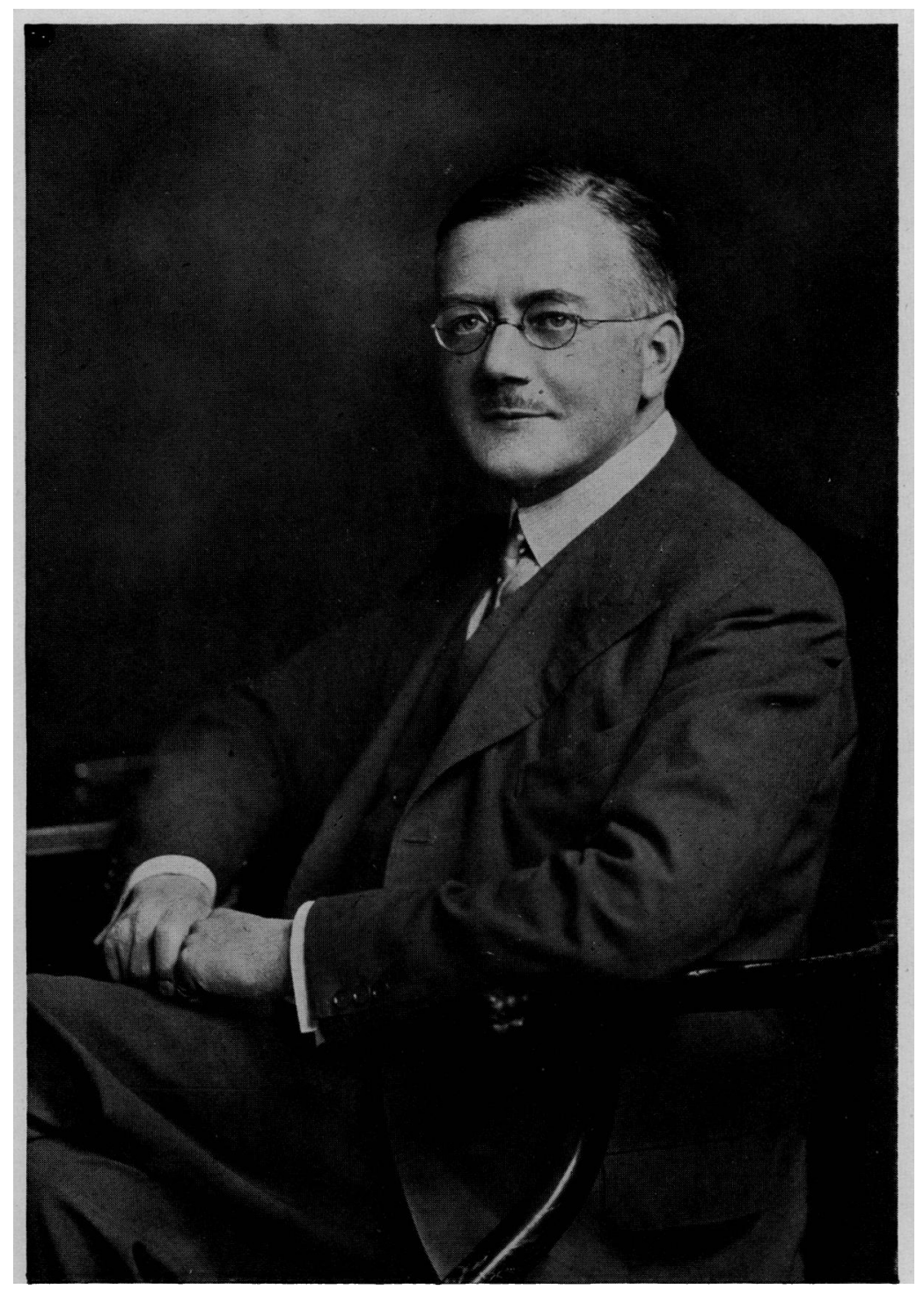

ARTHUR DONAID GRIFFITH

Photo by Lafayette 
his professional work. To his colleagues and assistants he was a sage counsellor to whom they invariably turned for advice and guidance. Always able to see beyond, the immediate tangle, his 'assessment of difficult situations was at one and the same time balm and positive help. Scrupulousness combined with exquisite judgment made him not merely an outstanding, but the outstanding figure in any team, even if his reticence always forced him away from the limelight. The same qualities showed themselves in his work as an ophthalmologist; his diagnoses were never sudden inspirations, but the logical deductions of a meticulous examination, whilst his operations were beautiful examples of effortless deliberation. Richly endowed with that talent that is born in the stream of life, his was essentially the genius that flowers in quietude. It was for this reason that so much of his activities was little known outside the circle of those who were privileged to work with him. It is only they who know how much of the spade-work on the use of radium and $\mathrm{X}$-ray therapy in ophthalmology was done by him and only his immediate collaborators who can assess how much Griffith, in his 35 years' service at the Royal Eye Hospital, contributed to the maintenance of established standards, to the elaboration of new levels of achievements and the formulation of new aspirations. At the Royal Eye Hospital which is perpetuating his cherished memory by a lectureship in optics, he will be remembered as a gentle colleague, a superb ophthalmologist and a formative force in the development of research facilities in ophthalmology. His colleagues feel that a quotation from Dante, whom in common with his charming Italian wife, he loved deeply and reverently is an apt epitaph :

$$
\begin{aligned}
& \text { "In te misericordia, in te pietate } \\
& \text { in te magnificenza, in te s'aduna } \\
& \text { quantunque in creatura e di bontate." }
\end{aligned}
$$

ARNOLD SORSBY.

\section{We have received the following appreciation from an old friend:}

Few men are as averse from extremes as Arthur Griffith was. Over emphasis.or exaggeration was decidedly distasteful to him. His words were chosen with care and deliberation. Vehement expression of opinion on his part was very rare indeed, whilst coarseness of thought or speech was anathema to him. His was a life of refinement of mind and spirit. The tenderness of heart and sensitiveness of his being were sometimes not known to those about him, for he was strangely shy.

When Griffith undertook a task, it was done with meticulous care. He could not be stampeded into ariy course of action. All his actions were under the government of his mind. He had amazing courage and forebearance. In spite of his shyness, he never evaded an issue just because of its unpleasantiness. He weighed his actions and his words with the greatest care. What he said, he meant. He would not say a thing thoughtlessly and so perchance give hurt. The other person was invariably given the right of having his own opinion; and it was respected; even though Griffith might differ from it very greatly indeed.

The courage Griffith displayed at the close of his life was characteristic of his whole life. His desperately distressing malady would have put into a panic of fear any less courageous person. His responses were purely natural and instinctive apprehensions. Stark fear never had a place in his being. 
Lurking behind a dignified and, at times, an austere presence was a delightful sense of fun and humour which his intimate friends often saw. He could laugh with the best. The more subtle the allusion, the more his appreciation.

Gentleness and tactfulness were ever his own. To the injured or the wounded. he was as gentle as a mother to her child. He was never soft or sloppy. His understanding of animals was a delight to behold. He understood them and they himat once. He has been seen to crawl on his hands and knees to play with his friend dog for the sheer delight it gave him to give pleasure to the dog.

The world is indeed much poorer for his passing.

\section{NOTES}

Ophthalmological Society of the United Kingdom Officers $1944-45$

THE following names were submitted for election at the Annual Congress on April 1. President, Charles Goulden; Vice-presidents, M. H, Whiting, Alex. MacRae, P. G. Doyne, John Marshall ; Treasurer, Sir Arnold Lawson ; Council, T., Keith Lyle, T. L. de Courcy, Air-Commodore P. C. Livingston, F. A. Anderson, George Black, Victor Purvis; Acting Hón. Secretary, Frank W. Law.

University of Glasgow

Post.graduate Lectures in Ophthalmology Whitsun Term 1944

DURING April and May a series of meetings will be held in the Department on Wednesdays at $8 \mathrm{p} . \mathrm{m}$. The general arrangements will be similar to the series held last year. Tea will be, served after the paper and a discussion will follow. The meetings will be open to all medical practitioners and senior students interested in Ophthalmology.

April 5, Mr. W. B. Inglis Pollock-“"The Antiquity of Ophthalmology"; April 12, Professor A. J. Ballantyne-" Ophthalmology and the Diabetic Patient"; April 19, Dr. Laurance D. W. Scott"The Diabetic Patient and Ophthalmology"; April 26, Dr. I. S. McGregor-" "Prognosis in Squint"; May 3, Dr. J. A. Conway"Ocular Therapeutics"; May 10, Dr. Dorothy Campbell-_"Industrial Disorders of the Eye."

Corrigendum *

MR. JOHN FOSTER points out that in his letter (p. 152), the word elucidate has been mis-spelt, and the rest of the sentence should read "nature or progress" instead of " nature of progress."

Special Notice

WE are asked by the Ministry of Information to state that the fact that goods made of raw materials in short supply owing to war conditions are advertised in this journal should not be taken as an indication that they are necessarily available for export. 